\title{
Anterior Uveitis Caused by Ocular Side Effects of Afatinib: A Case Report
}

\author{
Daisuke Todokoro $^{a}$ Hirotaka Itakura $^{b}$ Takashi Ibe $^{c}$ Shoji Kishi ${ }^{a}$ \\ ${ }^{a}$ Department of Ophthalmology, Gunma University Graduate School of Medicine, and \\ Departments of ${ }^{\mathrm{b}}$ Ophthalmology and ${ }^{\mathrm{C}}$ General Thoracic Surgery, Maebashi Red Cross \\ Hospital, Maebashi, Japan
}

\section{Key Words}

Afatinib - Epidermal growth factor receptor - Side effect - Anterior uveitis - Koeppe nodule . Unilateral granulomatous anterior uveitis

\begin{abstract}
Afatinib is a second-generation epidermal growth factor receptor (EGFR) inhibitor that has been shown to be effective against EGFR-mutated non-small cell lung cancer (NSCLC) resistant to conventional EGFR inhibitors such as gefitinib and erlotinib. Although ocular side effects of gefitinib and erlotinib have been reported, those for afatinib have yet to be definitively established. This report presents details on the first case of unilateral iridocyclitis associated with the side effects of afatinib therapy. A 75-year-old Japanese male ex-smoker with EGFR-mutated NSCLC underwent afatinib therapy for multiple metastases. At 2 weeks, bilateral conjunctivitis developed. Topical medication and a 1-week afatinib washout period resulted in the improvement of the conjunctivitis. However, 3 days after the resumption of afatinib, the patient developed unilateral granulomatous anterior uveitis in his right eye. Best-corrected visual acuity (BCVA) measurement indicated a decimal visual acuity of 0.2 , while the slit-lamp findings were characterized by granulomatous inflammation, keratic precipitates, Koeppe nodules and posterior synechiae. There was no evidence suggesting other intraocular inflammatory disease or metastatic tumor. The left eye was intact. The use of topical medication including steroids and a washout of afatinib resulted in a gradual subsiding of the anterior uveitis. After resolution of the anterior uveitis, oral afatinib was resumed. BCVA of the right eye finally recovered to a decimal acuity of 1.0. Ophthalmologists should be aware of the possibility that side effects associated with afatinib could cause granulomatous anterior uveitis.

\section{KARGER}

Daisuke Todokoro

Department of Ophthalmology

Gunma University Graduate School of Medicine

3-39-15 Showa-machi, Maebashi, Gunma 371-8511 (Japan)

E-Mail dtodokor@gunma-u.ac.jp 
Todokoro et al.: Anterior Uveitis Caused by Ocular Side Effects of Afatinib: A Case Report

\section{Introduction}

Afatinib is a second-generation epidermal growth factor receptor (EGFR) inhibitor that blocks ErbB-family receptors [1]. This inhibitor has been reported to be effective against EGFR-mutated non-small cell lung cancer (NSCLC) and can be used as an alternative to conventional EGFR inhibitors such as gefitinib and erlotinib, or as a first-line treatment [2, 3$]$. Previously reported ocular side effects of gefitinib and erlotinib include dry eye symptoms, blepharitis/meibomitis, trichomegaly, eyelid skin rash and anterior uveitis [4-8]. However, little is known about the ocular side effects associated with afatinib. In this report, we describe the first case of unilateral anterior uveitis, which was highly suspected to be secondary to the afatinib therapy.

\section{Case Presentation}

A 75-year-old Japanese male ex-smoker underwent four different video-assisted thoracoscopic surgeries for EGFR-mutated NSCLC and a pancreaticoduodenectomy for metastatic pancreatic tumor in 2006. In September 2014, he was diagnosed with metastatic thyroid tumor and received afatinib therapy in November 2014. Afatinib was the only chemotherapy administered to the patient. Two weeks after the initiation of an oral $40-\mathrm{mg}$ afatinib dose, the patient developed bilateral conjunctival injection without discharge and was referred to ophthalmologists. The best-corrected visual acuity (BCVA) measurements showed there was a decimal visual acuity of 0.9 in the right eye and 1.0 in the left eye. Slit-lamp examination revealed there was bulbar conjunctival injection and incipient senile cataract in both eyes. During these examinations, there were no clinical signs that suggested the presence of uveitis. The conjunctivitis resolved shortly after the instillation of bromfenac $0.1 \%$ eye drops twice a day and a 1-week afatinib washout period.

On the 3rd day after the patient resumed taking afatinib, he developed blurred vision in his right eye and once again visited his ophthalmologists. BCVA had decreased to a decimal acuity of 0.2 in his right eye, while it remained at 1.0 in his left eye. Slit-lamp examination revealed keratic precipitates, cells $(1+)$ in the anterior chamber, two small Koeppe nodules on the nasal iris, posterior synechiae and mild vitreous haze in the right eye (fig. 1a). There was no inflammation observed in the left eye. Fundus examination revealed no remarkable findings, including metastatic choroidal tumor. Intraocular pressure elevation, dendritic or pseudo-dendritic corneal epithelial lesion, iris atrophy, or histories of recurrent HSV infection or skin eruption were absent. The results of a serologic test including full blood counts, liver enzymes, kidney function, electrolytes, fasting plasma glucose and hemoglobin A1C revealed only mild anemia. Serologic tests for syphilis were negative. A chest X-ray and CT scan showed no hilar or mediastinal lymphadenopathy, and no signs of tuberculosis. Human leukocyte antigen (HLA) typing revealed that the patient was HLA-B27 negative. Since the unexplained uveitis that developed after the administration of afatinib was similar to that which has been observed for erlotinib, we considered the possibility of afatinib-induced uveitis. Based on these findings, we stopped the general afatinib treatment and then restarted topical betamethasone $0.1 \%$ four times per day and mydriatics once per day. After the inflammation gradually subsided, the topical betamethasone $0.1 \%$ was then tapered to twice per day and the mydriatics were discontinued. Although oral afatinib at a dose of $30 \mathrm{mg}$ was resumed after a 3-week washout period, the anterior uveitis in the right eye did not recur. The BCVA finally recovered to a decimal acuity of 1.0 after 6 months. However, the posterior synechiae remained (fig. 1b). There were no other structural complications observed. 
Todokoro et al.: Anterior Uveitis Caused by Ocular Side Effects of Afatinib: A Case Report

\section{Discussion}

EGFR is a transmembrane receptor that is ubiquitously distributed and constitutively expressed in normal epithelial tissues that include the skin, glands, hair follicles, and the conjunctival and corneal epithelium $[9,10]$. However, it is unknown whether the EGFR is expressed in the human iris pigment epithelium. Ocular side effects of EGFR inhibitors, such as dry eye symptoms, blepharitis/meibomitis, trichomegaly, and eyelid skin rashes, are understandable, as EGFRs are distributed in both the epidermal and epithelial tissues. However, both the mechanism and the reason why EGFR inhibitors rarely cause intraocular inflammation remain unknown. A mutation in the intracellular domain of the receptor not only results in overexpression, but has also been shown to be associated with tumor growth and progression [9]. Since first-generation EGFR inhibitors, which include gefitinib and erlotinib, are able to reversibly block only the EGFR, they are used as first-line chemotherapeutic agents for NSCLC with EGFR mutation [11-13]. Recently, afatinib, which irreversibly inhibits ErbB family members including EGFR, HER2 and HER4, has become available for use in treating the progression of NSCLC. Moreover, despite the availability of gefitinib and erlotinib, afatinib is now considered to be the first-line treatment for EGFR-mutated NSCLC [2, 3]. Various ocular side effects secondary to gefitinib and erlotinib have been previously reported when using these inhibitors [4-8]. Among them, bilateral anterior uveitis secondary to erlotinib has been shown to be a rare ocular side effect [6-8]. However, ocular side effects associated with afatinib have yet to be clearly established. Here, we report the details of the first case of unilateral anterior uveitis associated with afatinib therapy.

A number of medications have been shown to cause drug-induced uveitis, which can be quantitatively assessed by using the Naranjo algorithm [14,15]. Based on a Naranjo score of 5, the current case would be graded as 'Probable' due to the following findings: there are previous conclusive reports on their reaction $(+1)$; the adverse event appeared after the suspected drug was administered (+2); the adverse reaction improved when the drug was discontinued (+1); the adverse reaction did not reappear when the drug was readministered $(-1)$, and there were no alternative causes that, on their own, could have caused the reaction $(+2)$. Although afatinib-induced uveitis has not been previously reported, a prior study by Kawaguchi et al. [8] did report a case of bilateral erlotinib-induced uveitis that showed granulomatous inflammation accompanying Koeppe nodules. Thus, granulomatous anterior uveitis with iris nodules could possibly be a characteristic of EGFR inhibitor-induced uveitis. Although our current case only showed unilateral involvement, all other previous reports of uveitis secondary to erlotinib have been reported to be bilateral. In our current case, the patient developed bilateral conjunctival injection prior to the uveitis, which might be a symptom of anterior uveitis. If we had we not stopped the afatinib treatment, the possibility exists that uveitis might have developed in his left eye. However, the specific reason why only the right eye was involved remains unknown at present. After we stopped the afatinib treatment, our results showed that the topical use of steroid and mydriatics were effective in treating the afatinib-caused anterior uveitis. While the exact reason why the patient did not develop uveitis upon re-administration of the drug is unknown, one possibility might be that the dose was lower and/or there was continuation of the topical steroid.

In conclusion, the novel EGFR inhibitor afatinib induced granulomatous anterior uveitis accompanied by iris nodules. Ophthalmologists need to be aware of the possibility that druginduced uveitis could occur during the treatment of cancer in patients, even when the uveitis is unilateral. 
Todokoro et al.: Anterior Uveitis Caused by Ocular Side Effects of Afatinib: A Case Report

\section{Statement of Ethics}

Written informed consent was obtained from the patient for publication of this case report and any accompanying images.

\section{Disclosure Statement}

The authors declare that they have no competing interests. No funding was received for this work.

\section{References}

1 Solca F, Dahl G, Zoephel A, Bader G, Sanderson M, Klein C, Kraemer O, Himmelsbach F, Haaksma E, Adolf GR: Target binding properties and cellular activity of afatinib (BIBW 2992), an irreversible ErbB family blocker. J Pharmacol Exp Ther 2012;343:342-350.

-2 Schuler M, Fischer JR, Grohe C, Gutz S, Thomas M, Kimmich M, Schneider CP, Laack E, Marten A: Experience with afatinib in patients with non-small cell lung cancer progressing after clinical benefit from gefitinib and erlotinib. Oncologist 2014;19:1100-1109.

-3 Popat S, Mok T, Yang JC, Wu YL, Lungershausen J, Stammberger U, Griebsch I, Fonseca T, Paz-Ares L: Afatinib in the treatment of EGFR mutation-positive NSCLC - a network meta-analysis. Lung Cancer 2014;85:230-238.

4 Celik T, Kosker M: Ocular side effects and trichomegaly of eyelashes induced by erlotinib: a case report and review of the literature. Cont Lens Anterior Eye 2015;38:59-60.

5 Medina Mendez CA, Ma PC, Singh AD: Acquired trichomegaly: trichomegaly secondary to erlotinib. JAMA Ophthalmol 2014;132:1051.

-6 Ali K, Kumar I, Usman-Saeed M, Usman Saeed M: Erlotinib-related bilateral anterior uveitis. BMJ Case Rep $2011 ; 2011$

7 Lim LT, Blum RA, Cheng CP, Hanifudin A: Bilateral anterior uveitis secondary to erlotinib. Eur J Clin Pharmacol 2010;66:1277-1278.

8 Kawaguchi A, Takenobu F, Yamazaki A, Inoue Y: A case of uveitis following treatment with peroral erlotinib (in Japanese). Rinsho Ganka (Jpn J Clin Ophthalmol) 2012;66:1069-1072.

-9 Yano S, Kondo K, Yamaguchi M, Richmond G, Hutchison M, Wakeling A, Averbuch S, Wadsworth P: Distribution and function of EGFR in human tissue and the effect of EGFR tyrosine kinase inhibition. Anticancer Res 2003;23:3639-3650.

10 Liu Z, Carvajal M, Carraway CA, Carraway K, Pflugfelder SC: Expression of the receptor tyrosine kinases, epidermal growth factor receptor, ErbB2, and ErbB3, in human ocular surface epithelia. Cornea 2001;20:81-85.

11 Dhillon S: Gefitinib: a review of its use in adults with advanced non-small cell lung cancer. Target Oncol 2015;10:153-170.

-12 Reck M, van Zandwijk N, Gridelli C, Baliko Z, Rischin D, Allan S, Krzakowski M, Heigener D: Erlotinib in advanced non-small cell lung cancer: efficacy and safety findings of the global phase IV Tarceva Lung Cancer Survival Treatment study. J Thorac Oncol 2010;5:1616-1622.

13 Shepherd FA, Rodrigues Pereira J, Ciuleanu T, Tan EH, Hirsh V, Thongprasert S, Campos D, Maoleekoonpiroj S, Smylie M, Martins R, van Kooten M, Dediu M, Findlay B, Tu D, Johnston D, Bezjak A, Clark G, Santabarbara P, Seymour L: Erlotinib in previously treated non-small-cell lung cancer. N Engl J Med 2005;353:123-132.

-14 Naranjo CA, Busto U, Sellers EM, Sandor P, Ruiz I, Roberts EA, Janecek E, Domecq C, Greenblatt DJ: A method for estimating the probability of adverse drug reactions. Clin Pharmacol Ther 1981;30:239-245.

-15 London NJ, Garg SJ, Moorthy RS, Cunningham ET: Drug-induced uveitis. J Ophthalmic Inflamm Infect 2013;3:43. 


\section{Case Reports in \\ Ophthalmology}

\begin{tabular}{l|l}
\hline Case Rep Ophthalmol 2016;7:74-78 \\
\hline DOI: 10.1159/000444047 & $\begin{array}{l}\text { @ 2016 The Author(s). Published by S. Karger AG, Basel } \\
\text { www.karger.com/cop }\end{array}$ \\
\hline
\end{tabular}

Todokoro et al.: Anterior Uveitis Caused by Ocular Side Effects of Afatinib: A Case Report
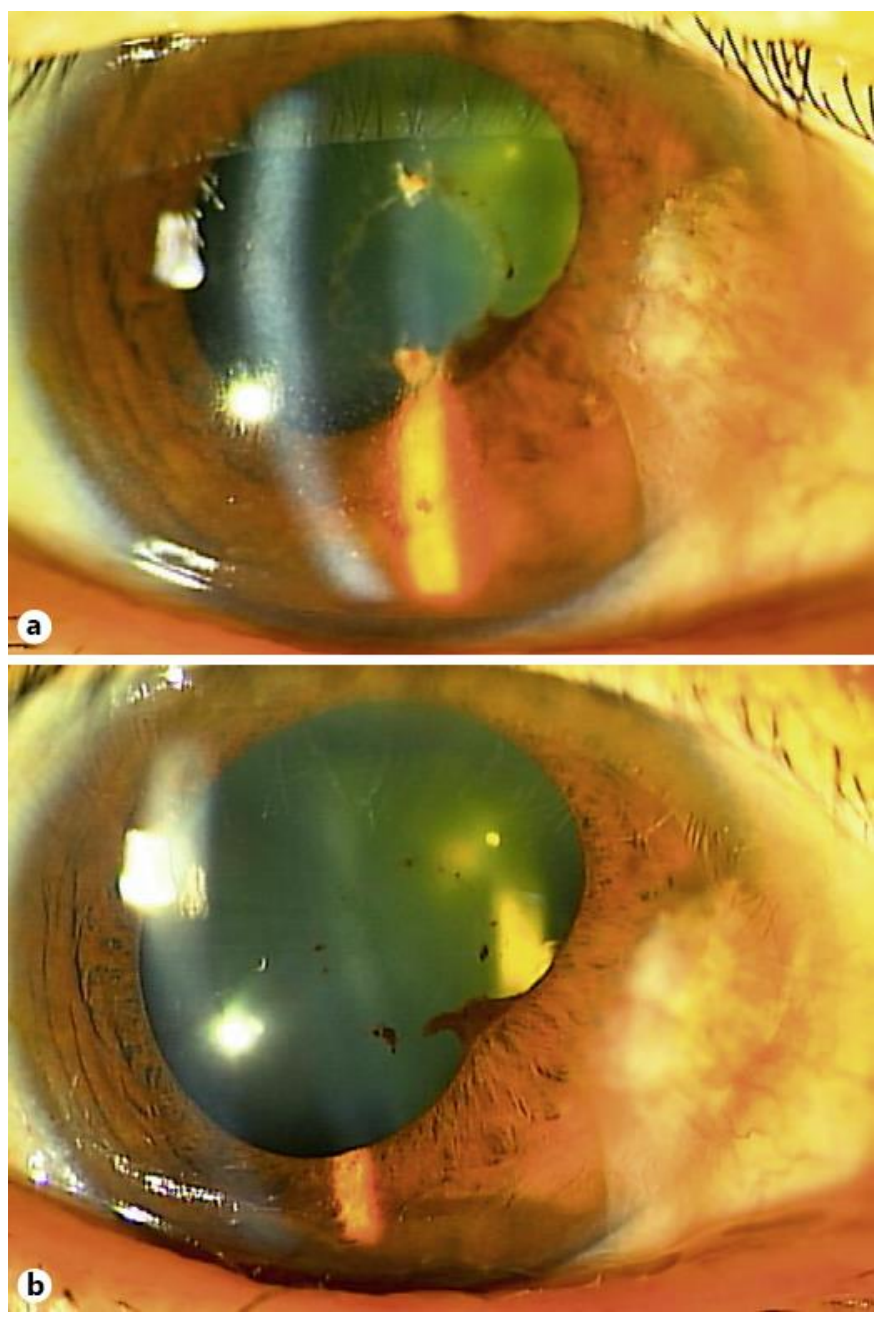

Fig. 1. Slit-lamp examination photographs. a Right eye at the onset of anterior uveitis. Keratic precipitates, cells $(1+)$ in the anterior chamber, two small Koeppe nodules on the nasal iris (not shown) and posterior synechiae were observed. BCVA measurement indicated a decimal visual acuity of 0.2 . b Right eye at 2 months after the onset of the anterior uveitis. The anterior chamber became clear while being treated with topical betamethasone $0.1 \%$ twice per day in spite of the resumption of oral afatinib at a lower dose of $30 \mathrm{mg}$. 